\title{
Study of Micro Grid Safety \& Protection Strategies with Control System Infrastructures
}

\author{
Md Razibul Islam, Hossam A. Gabbar
}

Faculty of Energy System and Nuclear Science, University of Ontario Institute of Technology, Oshawa, Canada.

Email: razu_49@hotmail.com, hossam.gabbar@uoit.ca

Received October $2^{\text {nd }}, 2011$; revised November $2^{\text {nd }}, 2011$; accepted November $10^{\text {th }}, 2011$

\begin{abstract}
Microgrids have been proposed in order to improve reliability and stability of electrical system and to ensure power quality of grid. Microgrid consists of low voltage distribution systems with distributed energy resources, such as wind turbine and photovoltaic power systems, together with storage devices. It is essential to protect a micro grid in both the grid-connected and the islanded mode of operation against all different types of faults. This paper describes micro grid protection and safety concept with central control and monitoring unit where multifunctional intelligent digital relay could be used. This central control \& monitoring infrastructure is used for adaptive relay settings strategy for micro grid protection. Also operational safety design concept and fault mitigation technique is proposed to ensure confidence in protection system.
\end{abstract}

Keywords: Micro Grid (MG); Distributed Generator (DG); Micro Grid Central Control (MCC)

\section{Introduction}

With the development of renewable energy, energy storage and distributed generation (DG) the microgrid has attracted more and more concern due to its special features. A micro grid consists of a low to medium voltage network of small load clusters with DG sources and storage. Micro grids can operate in an islanded mode or can be connected to the main grid system. If a micro grid is connected to the system, it is seen as a single aggregate load or source. One of the potential advantages of a micro grid is that it could provide a more reliable supply to customers by islanding from the system in the event of a major disturbance. As distributed generator placed/situated close to the load, it has the advantage of reducing transmission losses as well as preventing network congestions [1,2]. Thus distributed generator can enhance system reliability and stability.

Micro grids currently offer various advantages to endconsumers, utilities and society, such as: Improved energy efficiency, improve power quality and reliability, minimized overall energy consumption, reduced greenhouse gases and pollutant emissions, cost efficient electricity infrastructure replacement [1-5].

\section{Intelligent Protection Strategy of Micro Grid}

One of the major challenges of micro grid protection system is that it must respond to both island and grid connected faults [1-13]. In the first case the protection system should isolate the smallest part of the micro grid when clears the fault. In the second case the protection system should isolate the micro grid from the main grid as rapidly as necessary to protect the micro grid loads [13].

Modern micro grid consist of many different distributed energy resources like solar PV, wind turbines, fuel cells, small-scale hydro, tidal and wave generators, microturbines, combined heat power (CHP) systems, energy storage, etc.. When different type of distributed resource connected to micro grid and Utility grid, the DR contribute fault current to the system and the contribution level depends on distribution resource type. To ensure safe operation of micro grid the protection equipment should be updated accordingly.

So the dynamic structure of micro grid and their various operating conditions required the development of adaptive protection strategies. One such strategy is proposed in Figure 1. Here central control unit communicate with all relays and distributed generators in the micro grid to record their status as ON/OFF, their rated current and their fault current contribution. Communicate with relay is required to update the operating current and to detect the direction of the fault currents and thus mitigate the fault properly. The control unit also records the status of utility grid as connected or micro grid is 


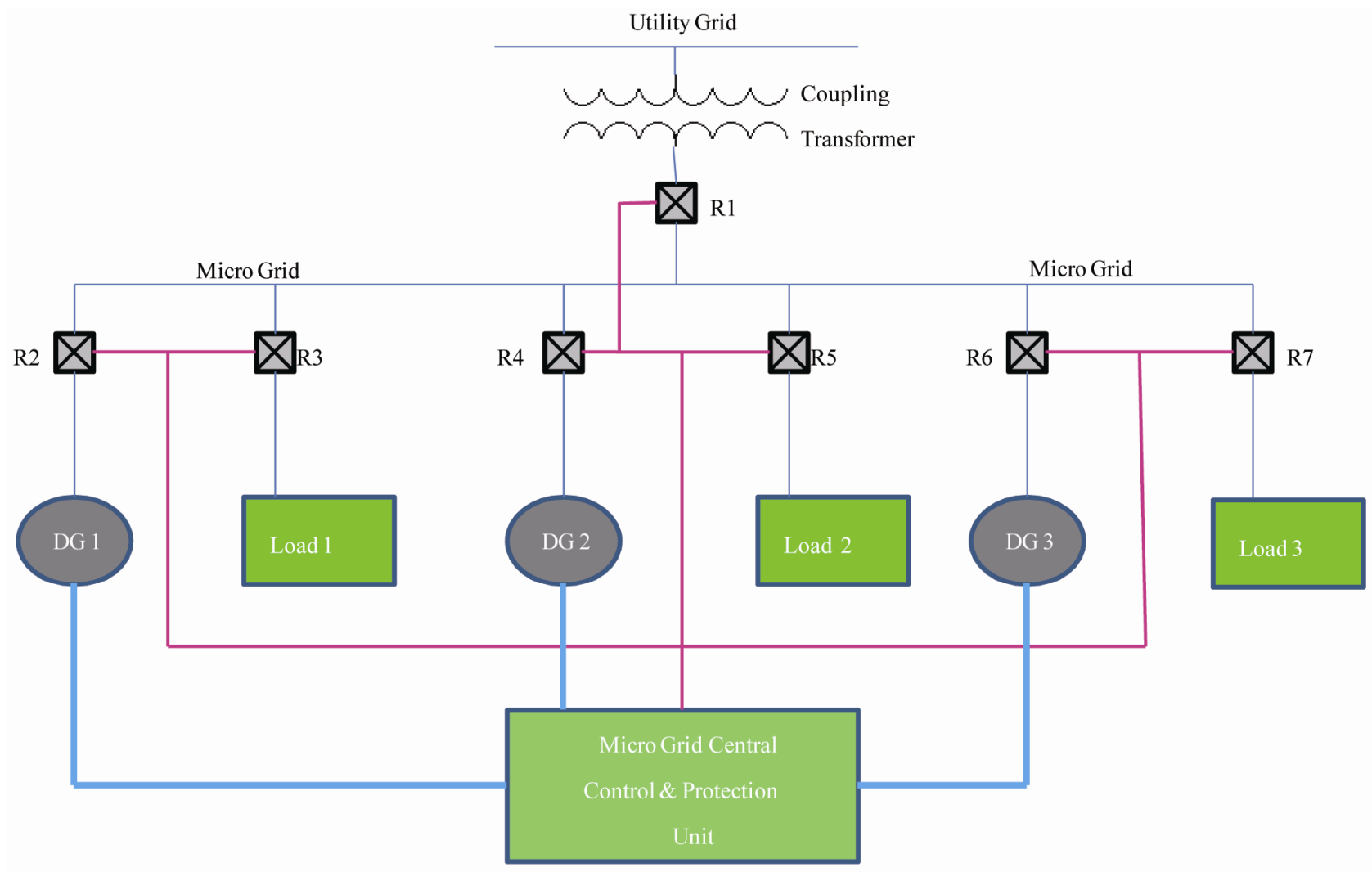

Figure 1. Topology of micro grid protection system.

islanded for adaptive protection.

\section{Operational Safety Design Concept of Micro Grid}

Safety analysis or safety design concept is important in micro grid protection and their fault analysis. Proper safety model provides appropriate level of confidence in protection system.

The intelligent control and monitoring unit need to meet the safety requirements which provide on basis of safety design criteria. Proposed operational safety of micro grid is shown in Figure 2. Central control and protection system should design to ensure required safety. Micro grid hazard analysis is important to design safety system and based on hazard level different safety threshold is settled. For micro grid safety design there are six parameters need to consider which are shown in Figure 2.

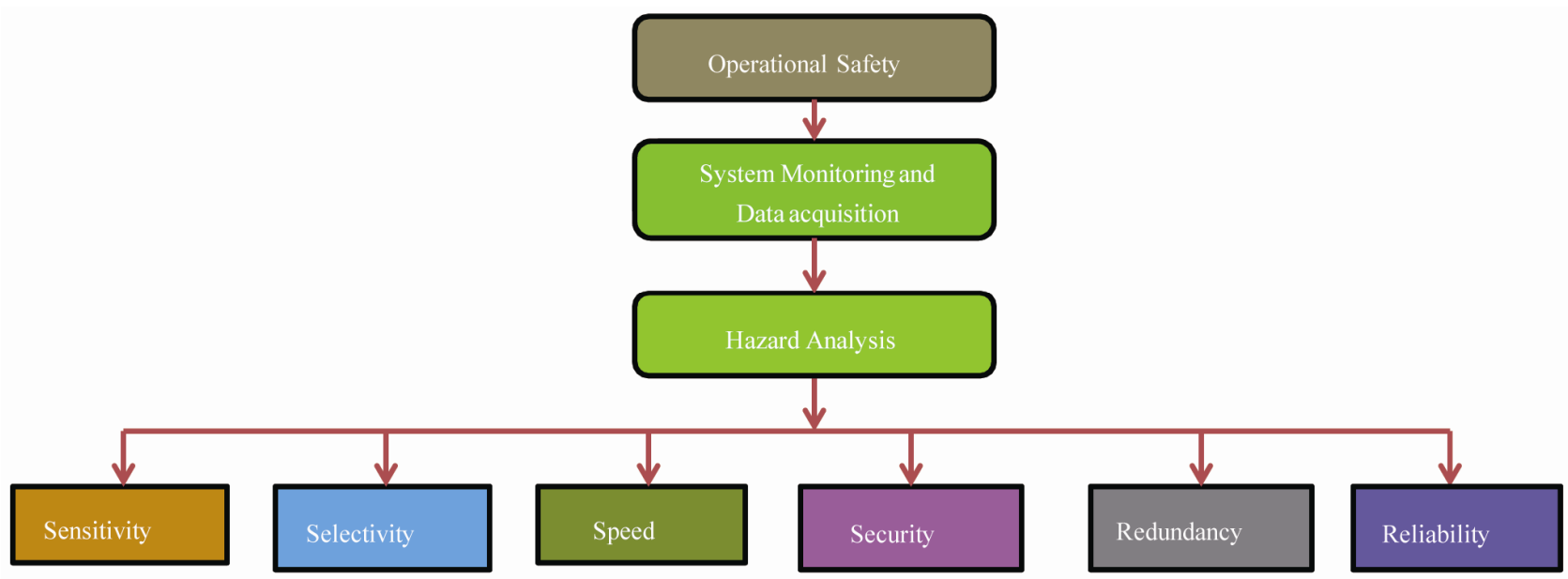

Figure 2. Operational safety design of micro grid. 
The first one is sensitivity, there should have nominal threshold value and control/protection system able to identify any abnormal condition. This nominal value should be set considering safety level of all power system equipment's. Second is selectivity, when fault detected in a system based on voltage, current and power direction fault zone is determined. In order to minimize fault consequence, the protection/control system should disconnect only the faulted part (Disconnect smallest possible part containing the fault). Third one is speed, in order to avoid damage to equipment and maintain stability protective relay should respond in the least possible time in any abnormal condition. This is very important from safety point of views.

The security level should be high, all the abnormal conditions/events of power system are not fault. So protection/control system should operate only when required to operate, reject all abnormal events and transients those are not fault. And the protection system should be designed to avoid misoperation while itself experiencing a credible failure. There should have redundancy options, redundant system are planned and referred as backup protection to ensure level of safety. The protection system should have redundant functionalities of relays to improve system reliability and safety. Different protection principle could be combining to reach protection redundancy. The reliability should be high, modern power system with distributed generator becoming more dynamic structure, so now reliability becomes important topic in control and protection system analysis. Based on different system condition there should have option for different relay setting. To improve modern protection and control system reliability and faster restoration of outage, we can use microprocessor based distribution relay or digital relay.

The above safety model could guarantee micro grid protection. We need to consider this safety model for both island and grid connected operation. It is essential to protect a micro grid in both the grid-connected and the islanded modes of operation against all types of faults.

The major issue arises in island operation with inverter-based sources. Inverter fault currents are limited by the ratings of the silicon devices to around 2 p.u. rated current. Fault currents in islanded inverter based micro grids may not have adequate magnitudes to use traditional over-current protection techniques. This possibility requires an expanded protection strategy [2,3].

Based on safety analysis a modern micro grid operational model for different relay settings is shown in Figure 3. In this proposed system, the central unit communicates with every single relay and distributed generator in the micro grid on interruption basis. The central control and monitoring unit record the instantaneous status of the distributed generator and utility grid as connected/ disconnected, their rated currents and their fault current contributions.

To overcome protection challenge of islanded and grid connected system different relay settings are required. Once a distributed generator connected/disconnected in system, based on island or grid connected, new relay

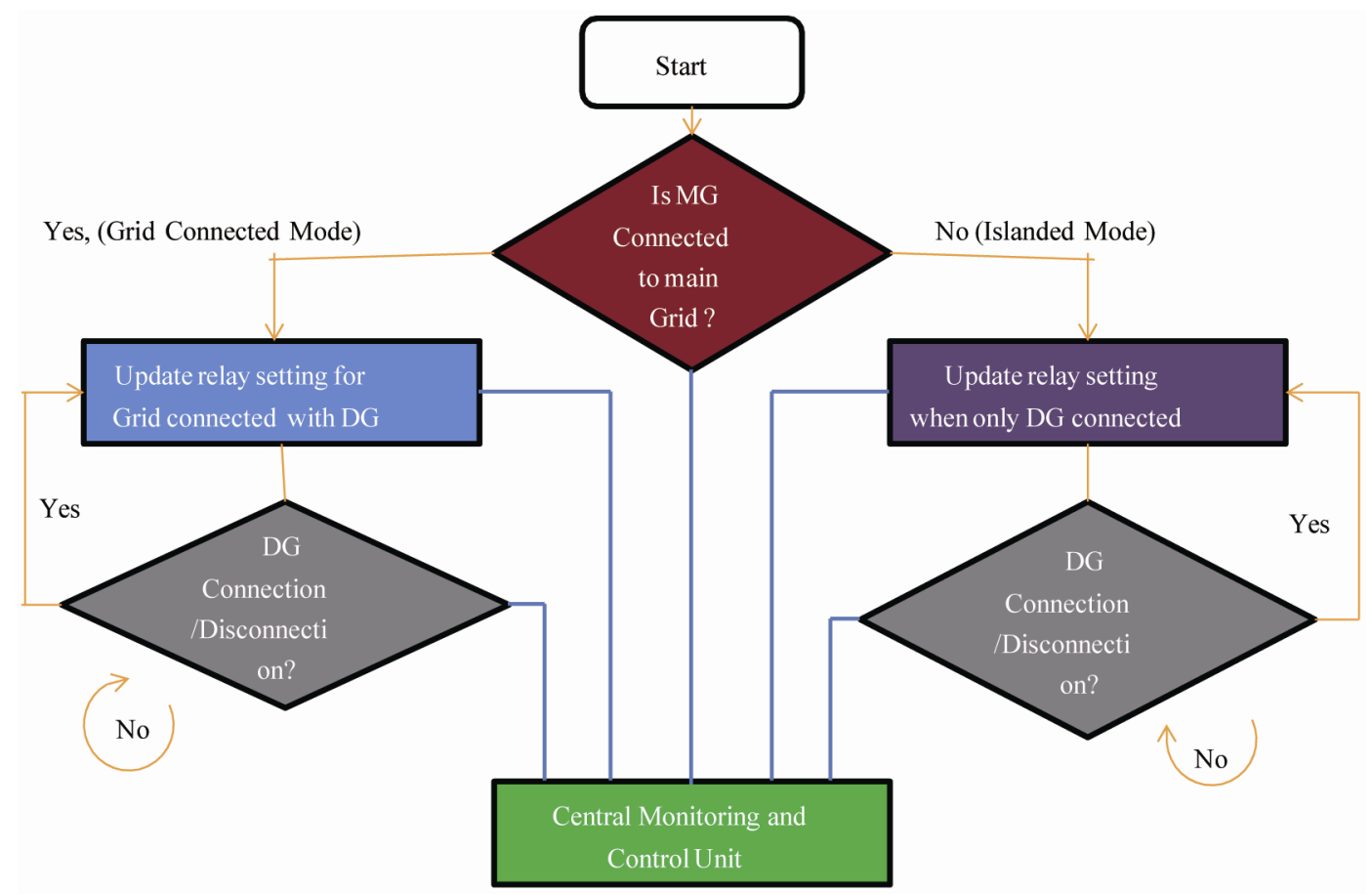

Figure 3. Micro grid operation model for different relay settings strategy. 
settings are updated, new fault currents are updated in relays. Relays operate independently to open the connections. Once the current flowing over the relay exceeds the operating current, relays send signals to set the fault detection bit.

\section{Micro Grid Fault Analysis with System Modeling}

In micro grid fault analysis we can categorize mainly two type, external fault (main grid) and internal fault (micro grid). External fault could be in MV bus or distribution transformer and internal fault could be in LV feeder or LV consumer. As micro grid need to operate in both island and grid connected mode there have challenge in micro grid protection system with conventional protection strategy [1-5]. The major micro grid protection problem is related to large difference between fault current in main grid connected and islanded mode.

Also there have sensitivity and selection problem due to different fault current in different scenario $[1,4]$. But it is essential to have high sensitive to faults and selectively isolate/sectionalize in the case of DGs with low fault current level. As conventional protection system don't offer solution for all micro grid protection challenge, advanced protection strategy required.

\section{Intelligent Protection Techniques for Micro Grid}

Here a model of adaptive/intelligent protection system for micro grid is shown in Figure 4. This advanced protection system can potentially solve the problems identified earlier. The protection scheme must ensure safe operation of the micro grid in both mode of operation, that is the grid connected mode and island mode. Due to contribution of host grid in grid connected mode fault currents are large. This allows to employment of conventional overcurrent relay, but the fact is that due to existence of distributed resources (DRs) the protection coordination may be compromised or even entirely loss in some cases [10].

However, in islanded mode due to limited current con-

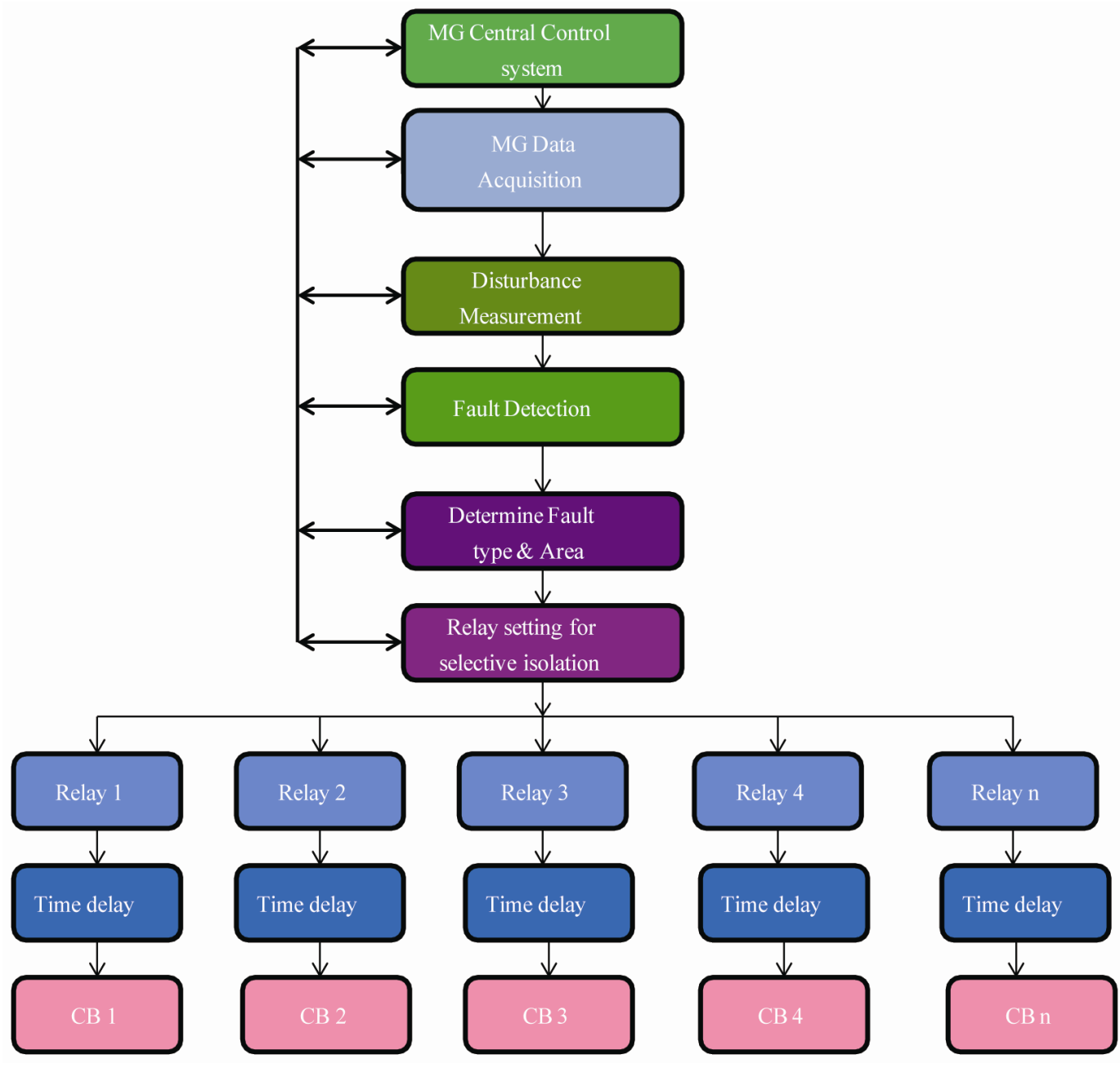

Figure 4. Centralized protection system for micro grid. 
tribution of distributed resource fault current may be significantly small compared to grid connected mode. For this reason the conventional over current protection is ineffective in islanded mode of operation [10].

Proposed adaptive protection system can solve the challenge of conventional micro grid protection system. The new protection system modifies the preferred protection response to a change in system conditions in a timely manner by means of externally generated signal or advanced control actions [1]. For a practical implementation of adaptive micro grid protection the requirements and suggestion can be mentioned as below:

Firstly, there would have a micro grid central controller (MCC) and monitoring system in modern micro grid protection system. Communication electronics make each $\mathrm{CB}$ with an integrated directional $\mathrm{OC}$ electronic trip unit (relay) capable of exchanging information with MCC.

Secondly, use of numerical directional OC relays $/ \mathrm{mi}-$ croprocessor based relay/digital relay because fuses or electromechanical and standard solid state relays are (especially for selectivity holding) inapplicable - they do not provide the flexibility for changing the settings of tripping characteristics and they have no current direction sensitivity feature.

Thirdly, numerical directional OC relays/microprocessor based relays must dispose of possibility for using different tripping characteristics (several settings groups) that can be parameterized locally or remotely automatically or manually $[1,14]$.

Finally, introduce modern control infrastructure and data acquisition protocols so that individual relays can communicate and exchange information with micro grid central controller (MCC). With this instantaneous settings for different fault scenario which will reliably to guarantee a required application performance.

The modern Micro grid protection system with micro grid central control and monitoring system is an important topic to discuss to overcome challenge of conventional protection system. Instantaneous relay settings, current, voltage and power directions are sent to central control unit through micro grid monitoring and data acquisition unit.

So with MCC and monitoring unit any abnormal condition or disturbance can be monitor and measure. Based on disturbance data analysis the fault could be detected, when any fault is detected it is important to find fault type based on current state of micro grid and the fault affected area/zone.

The main goal of intelligent protection system is to maintain relay setting of each relay with current micro grid scenario. There would be a special module in micro grid central control (MCC) unit which is responsible for periodic check and update of relay settings $[1,2]$. The Micro grid central control (MCC) can read data (direc- tion, electrical value, status) of individual relays from each $\mathrm{CB}$ and if required it can modify subset of relay settings (tripping characteristics).

So tripping decision can perform by MCC to each individual relay, in case of any abnormal situation is detected tripping condition is checked and the direction of current is measured compared with actual relay settings $[1,2,14]$.

\section{Fault Mitigation Technique of Micro Grid}

A simple model of micro grid protection structure and fault mitigation process is described in Figure 5. Micro grid protection system and fault analysis done based on data acquisition from control and monitoring unit. Based on data acquisition disturbance is measured and fault detection alarm found based on disturbance value.

At first fault should be determined by detecting change in bus bar voltage. Power direction is measured and based on this fault location detected. The fault point is in the utility grid if the power direction of the common connection point of utility grid and point of micro grid is positive. The direction of bus bar pointing to the line sets as power positive direction. According to the power directions of the lines connected to bus bar, the system can determine whether there is a bus short-circuit fault.

The fault is a bus short circuit fault and breakers of

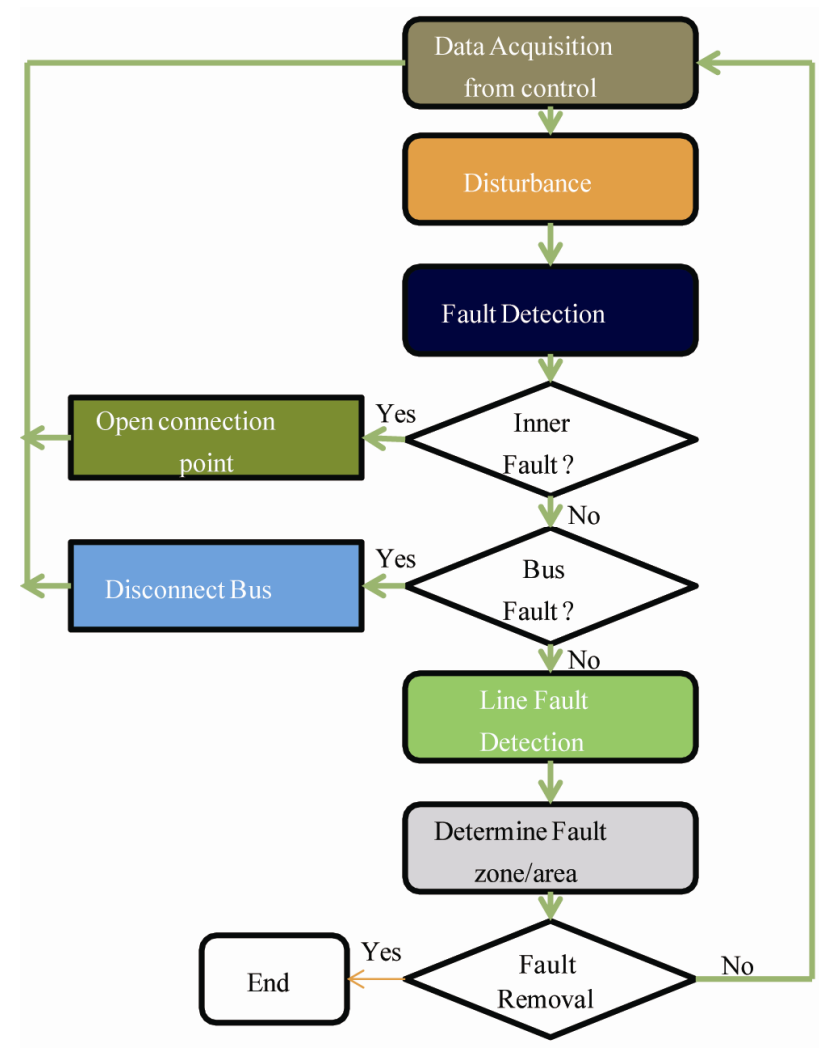

Figure 5. Fault mitigation technique of micro grid. 
each side of bus trip, if the power directions of all micro source lines are negative directions. Based on power direction inner fault, bus fault, line fault is determined. Once line fault is detected fault area/zone is determined and then fault is removed by tripping signal from relay.

\section{Case Study on Micro Grid Protection}

An example of intelligent protection system is shown in Figure $6[2,6]$. Here micro grid central controller (MCC) and monitoring system is included in conventional protection system. MCC is carried out by a programmable logic controller (PLC), a station computer sitting in MV/ LV substation. The function of communication electronics is to make each circuit breaker with an integrated over current relay capable of exchanging information with MCC [6].

MCC can read data (electrical value, status) from $\mathrm{CBs}$ if necessary it can modify relay settings. When any abnormal condition is detected a tripping condition is checked, if tripping condition is reached a $\mathrm{CB}$ is open.

For fault analysis we assume micro grid with distributed energy resource switched on the grid. Let assume there is a considerable change in micro grid and status of distributed energy resource.

SWB4 and SWB5 is disconnected for a maintenance work and SWB5 and SWB6 are supplied via SWB3 (CB3.2 and CB6.2 are closed) which is shown in Figure 7 from reference [2]. Two identical distributed generators are connected with SWB1 and SWB6 [2].

Now we analyze the fault between SWB1 and SWB2 (Figure 7), it is required to isolate the fault from the main grid side by CB1.2 and there is no selectivity and detection problem, also because the fault current seen by CB1.2 becomes higher Ikmax $=15 \mathrm{kA}$ (Figure 8) in the base case due to a contribution from the distributed resource in SWB1. CB2.1 is seen $2 \mathrm{kA}$ fault current supplied by second distributed generator in SWB6. It can only activate the L part of the relay's trip curve with the expected tripping time delay of $40 \mathrm{~s}$. So, by the (followme) function of CB1.2, CB2.1 is opened and isolates the fault from the LV feeder side in ts $=150 \mathrm{~ms}$ [2].

Here noticeable thing is ts $\geq 150 \mathrm{~ms}$ set for the OC relay in CB1.2 which may affect a stability of the distributed generator with a small inertia in SWB1. For all relay in the micro grid the time delay ts is set at $50 \mathrm{~ms}$. Then blocking signals are sent in correct directions which prevents an unnecessarily disconnection of distributed resources and healthy parts of the micro grid [2].

Now we assume that after an isolation of the first fault occurred in between SWB1 and SWB2, the island which includes SWB2, 3, 5, 6. The Distributed generator in SWB6 is switched to a frequency control mode and additionally each load in the island is dropped from $100 \mathrm{~A}$ to $50 \mathrm{~A}$.

Assume in between SWB2 and SWB3 there is a second fault inside the islanded micro grid and all non-directional OC relays use ts settings from the base case [2]. Ideally, the fault should be cleared by CB2.2 and CB3.1. Since there is no fault current source in SWB2, CB2.2 can't trip but it can be opened by the "follow-me" function of CB3.1. In case of using directional OC protection ts $=150 \mathrm{~ms}$ for CB3.1 [2]. However, the maximum fault current supplied by the synchronous DER in SWB6 and seen by CB3.1 Ikmax = 2.4 kA shown in Figure 9 .

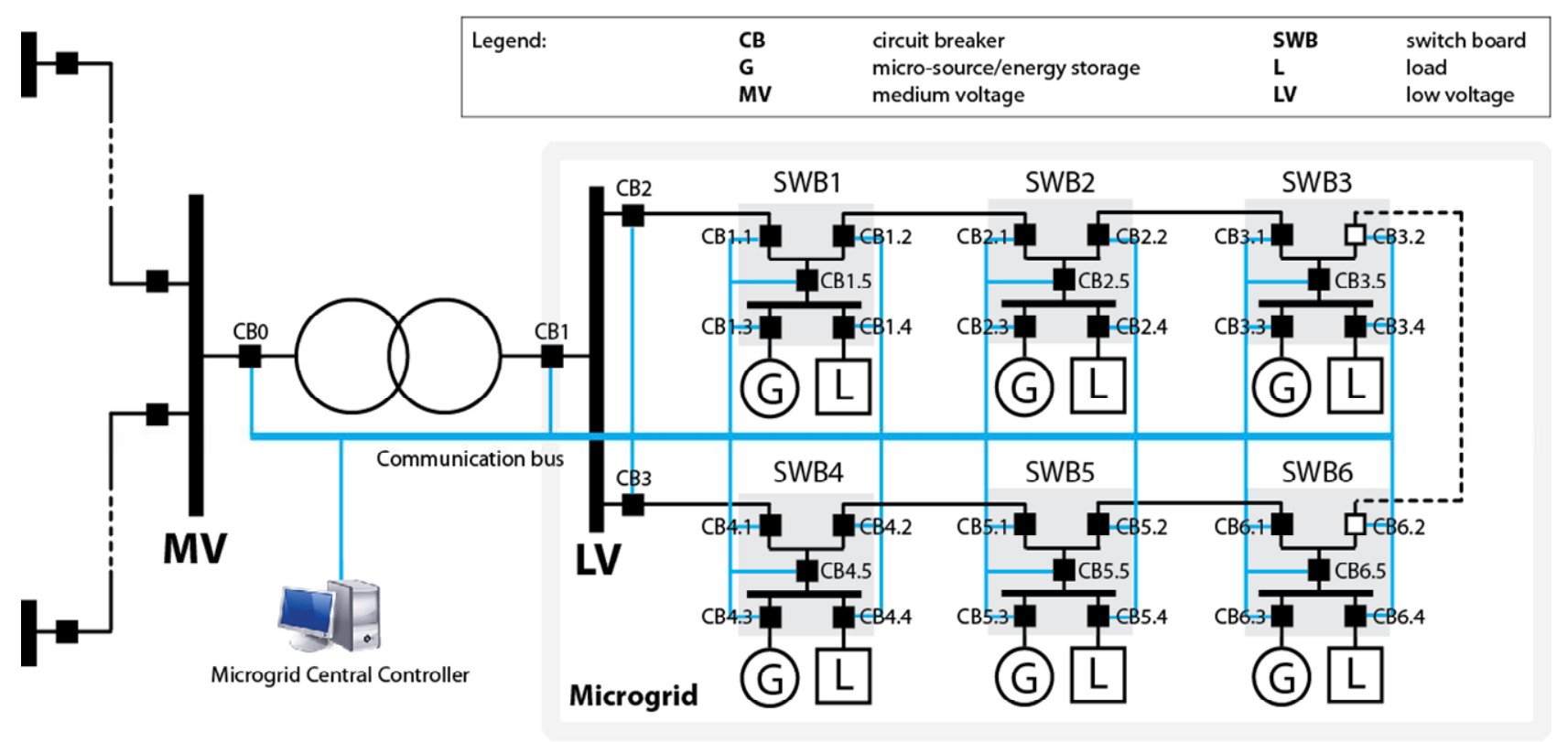

Figure 6. Micro grid protection system infrastructure. 


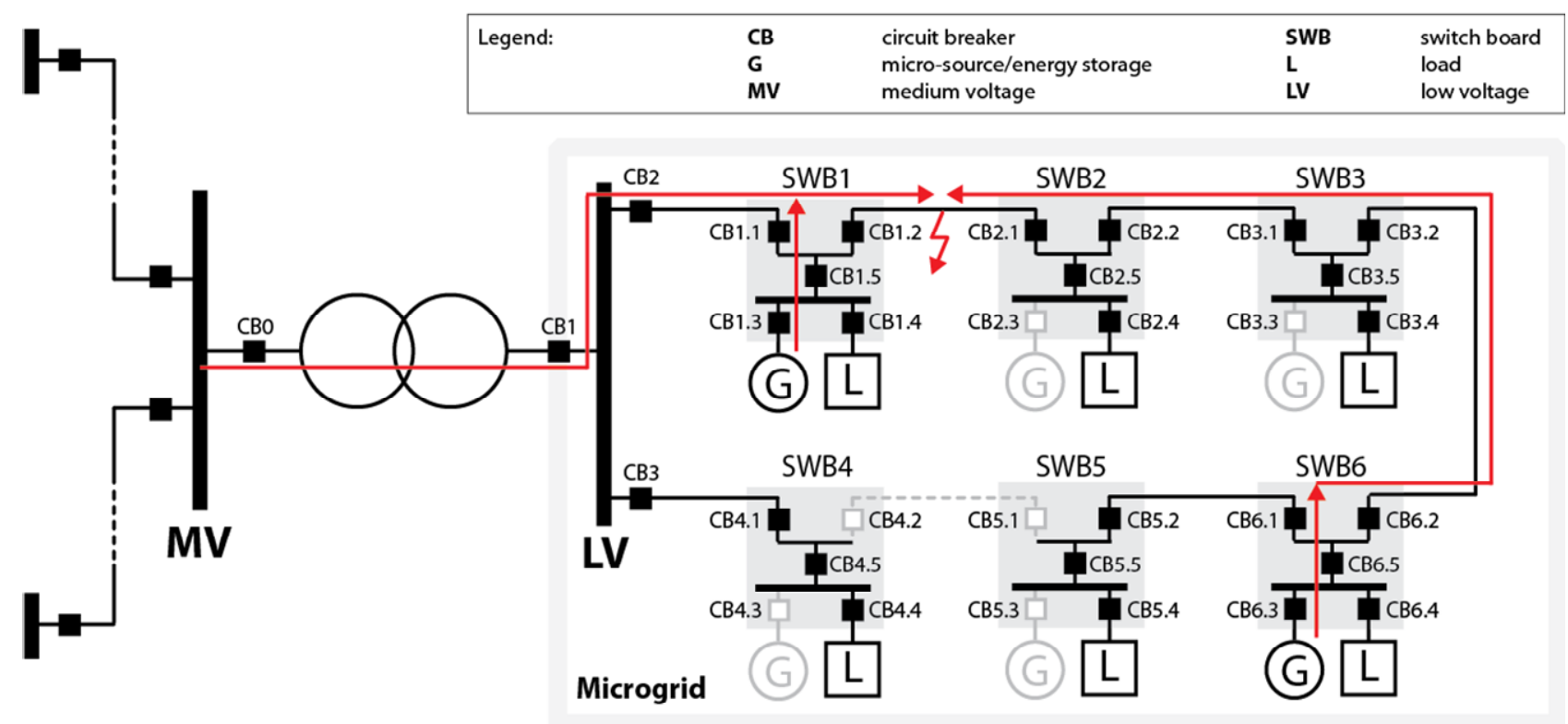

Figure 7. Micro grid protection system with central controller unit.

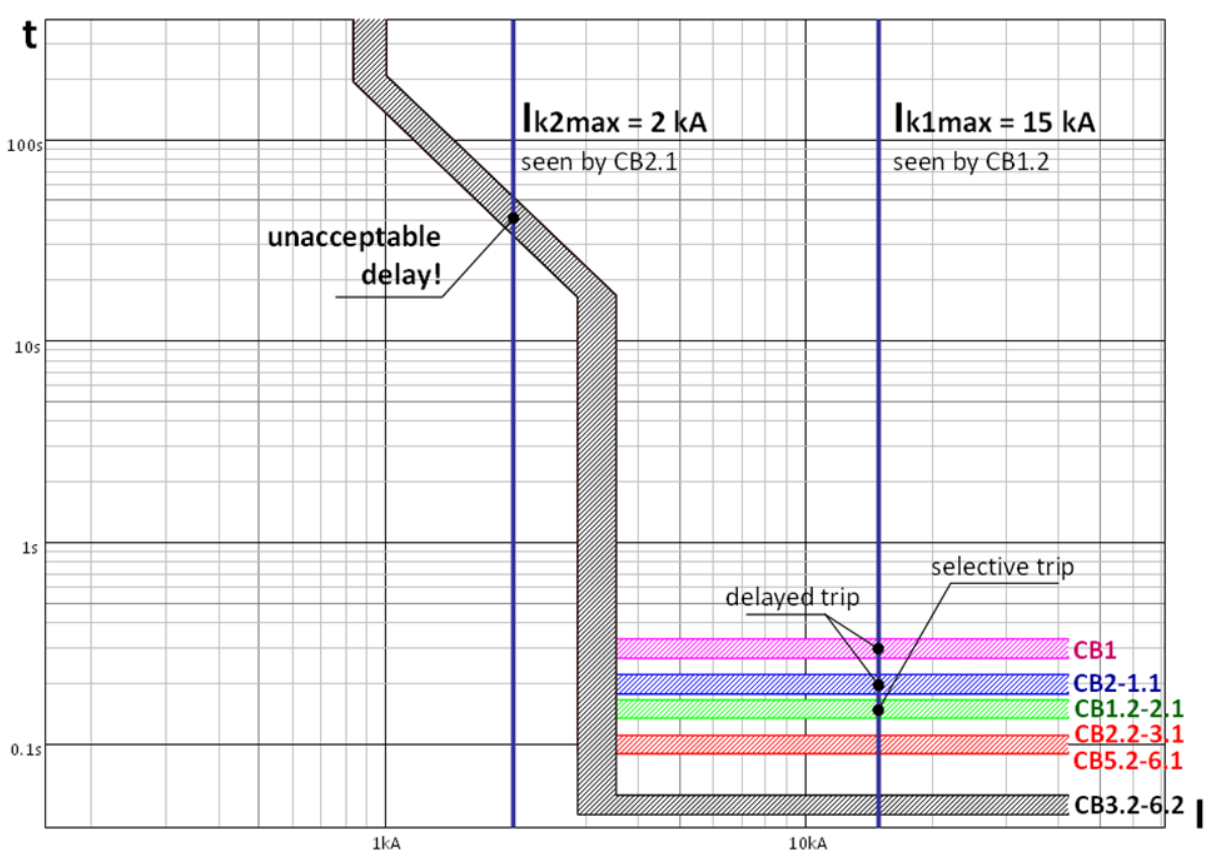

Figure 8. Base case trip curve and tripping sequence with directional overcurrent protection.

This will activate the L part of the relay's trip curve with the expected tripping time delay of $25 \mathrm{~s}$. During this time distributed generator in SWB6 will be disconnected by its out-of-step protection.

In island mode where the main grid does not contribute to the fault, to guarantee fast fault isolation the trip curve must be pushed to the left dynamically depending on the micro grid topology and a number of connected DG. The modified trip curves are illustrated in Figure 9 $[2,15]$.

\section{Conclusions}

Modern numerical relay normally offer several settings group which can be activated at any time. It can achieve instantaneous tripping in different fault and operation scenario. One of the challenges of micro grid protection is to operate during normal and island operation which could be solved by modern numerical relay with micro grid central control and monitoring unit.

In this paper, an intelligent micro grid protection system using digital relaying with central control and moni- 


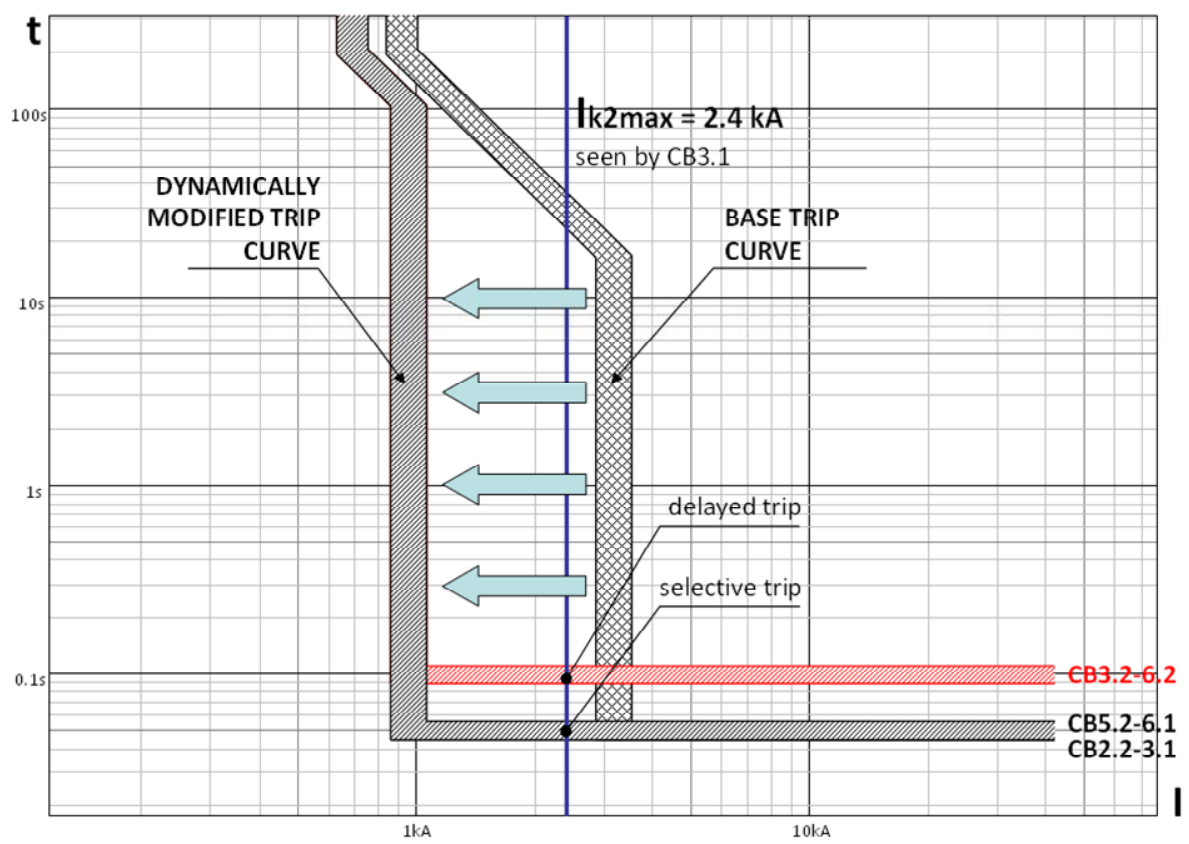

Figure 9. Base case and modified trip curves and a tripping sequence.

toring infrastructure is proposed. Safety model is analyzed to improve protection level. Multifunctional Intelligent Digital Relay permits automatic adaptation of protection settings according to the actual type of grid structure and the interconnection of micro grid. These intelligent digital relays allow for continuous measure and monitor analog and digital signal originated from the system.

Automated fault analysis is another important requirement for micro grid protection and safety. Modern microprocessor based/digital relay offer new approach based on pattern recognition and accurate fault location which are more reliable and secure than distance protection.

\section{REFERENCES}

[1] A. Oudalova and A. Fidigattibfd, "Adaptive Network Protection in MICROGRID,” 2011. www.microgrids.eu/documents/519.pdf

[2] A. Oudalova, "Advanced Architectures and Control Concepts for MORE MICROGRIDS," 2011. www.microgrids.eu/documents/654.pdf

[3] H. Nikkhajoei and R. H. Lasseter, "Microgrid Protection," IEEE PES General Meeting, Tampa, 24-28 June 2007, pp. 1-6.

[4] X.-P. WANG, Y. Li and Y.-Y. YU, "Research on the Relay Protection System for a Small Laboratory-Scale Microgrid System," Proceedings of the 6th IEEE Conference on Industrial Electronics and Applications, Beijing, 21-23 June 2011, pp. 2712-2716.

[5] T. S. Ustun, C. Ozansoy and A. Zayegh, "A Microgrid Protection System with Central Protection Unit and Extensive Communication," Proceedings of the 10th Inter- national Conference on Environment and Electrical Engineering, Rome, 8-11 May 2011, pp. 1-4.

[6] B. Su and Y. Li, "Trends of Smarter Protection for Smart Grid," East China Electric Power, Vol. 36, No. 7, 2008.

[7] S. P. Chowdhurya, S. Chowdhurya and P. A. Crossleyb, "Islanding Protection of Active Distribution Networks with Renewable Distributed Generators: A Comprehensive Survey," Electric Power Systems Research, Vol. 79, No. 6, 2009, pp. 984-992. doi:10.1016/j.epsr.2008.12.012

[8] T. S. Ustun, C. Ozansoy and A. Zayegh, "A Central Microgrid Protection System for Networks with Fault Current Limiters," Proceedings of the 10th International Conference on Environment and Electrical Engineering Rome, 8-11 May 2011, pp. 1-4.

[9] S. M. Brahma, "Development of Adaptive Protection Scheme for Distribution Systems with High Penetration of Distributed Generation," IEEE Transactions on Power Delivery, Vol. 19, No. 1, 2004, pp. 56-63. doi:10.1109/TPWRD.2003.820204

[10] M. A. Zamani, T. S. Sidhu and A. Yazdani, "A Protection Strategy and Microprocessor-Based Relay for Low Voltage Microgrid," IEEE Transactions on Power Delivery, Vol. 26, No. 3, 2011, pp. 1873-1883. doi:10.1109/TPWRD.2011.2120628

[11] J. Wei, Z.-Y. He and Z.-Q. Bo, "The Overview of Research on Microgrid Protection Development," International Conference on Intelligent System Design and Engineering Application, Changsha, 13-14 October 2010, pp. 692-697.

[12] J. A. P. Lopes, C. L. Moreira and A. G. Madureira, "Defining Control Strategies for MicroGrids Islanded Operation," IEEE Transactions on Power Systems, Vol. 21, No. 2, 2006, pp. 916-924. doi:10.1109/TPWRS.2006.873018

[13] J. Driesen, P. Vermeyen and R. Belmans, "Protection Issues in Microgrids with Multiple Distributed Genera- 
tion Units," IEEE Power Conversion Conference, Nagoya, 2-5 April 2007, pp. 646-653.

doi:10.1109/PCCON.2007.373034

[14] E. Sortomme, S. S. Venkata and J. Mitra, "Microgrid Protection Using Communication-Assisted Digital Relays,"
IEEE Transactions on Power Delivery, Vol. 25, No. 4, 2010, pp. 2789-2796.

[15] ABB SACE, "Working with the Trip Characteristic Curves of ABB SACE Low Voltage Circuit Breakers," White Paper, Vol. 1, 2007. http://www.abb.com/ 